\title{
Edith Sitwell (1887-1964)
}

\author{
Maria Teresa Gibert Maceda
}

En los últimos años, la conmemoración de aniversarios de personajes ilustres está dando lugar a a una auténtica industria. A través de la prensa, radio y televisión, diariamente nos llegan noticias de celebraciones de este tipo. En particular, el centenario del nacimiento de un autor prestigioso se está convirtiendo en motivo casi obligado para la organización de seminarios y congresos, coloquios y conferencias, encuentros y exposiciones, y para la publicación de números monográficos de revistas especializadas, obras críticas individuales o colectivas, artículos en periódicos y otras muchas manifestaciones de diversa índole. Sin duda existen precedentes en el pasado siglo, pero tenemos la impresión de que nunca se habían alcanzado las dimensiones actuales, tal vez porque los llamados medios de comunicación social difunden lo que en otros tiempos se restringía a pequeños círculos. El mundo académico participa y siente tal grado de entusiasmo por esta moda que podemos citar numerosos ejemplos de trabajos de investigación acabados precipitadamente o retenidos con el único fin de hacerlos coincidir en la fecha propicia.

Aunque el fenómeno tiene carácter universal, probablemente sea en la cultura anglosajona donde conozca un mayor auge, quizás por darse en ella una habitual convergencia de los intereses científicos y los cmerciales. Observemos, por ejemplo, la forma en que las poderosas editoriales universitarias - tanto británicas como norteamericanas- aprovechan estas ocasiones para publicar determinados títulos. Centrándonos en el campo de la literatura del siglo XX en lengua inglesa, si 1982 fue el año de James Joyce y Virginia Woolf, 1985 tuvo como protagonistas a Ezra Pound y D. H. Lawrence y ya se prepara un 1988 dedicado a T.S. Eliot y en menor medida a Eugene O'neil. Pero, junto a estas grandes figuras cuyos aniversarios motivan el que los estudiosos intensifiquen su atención hacia ellas y den a conocer opiniones más o menos originales ante la necesidad de satisfacer la curiosidad general, existen otras de las que poco nos ocupariamos si en semejantes ocasiones no se nos recordase su existencia.

Así pues, aceptando una cierta incomodidad por participar en este género "conmemorativo" (cincuentenarios, centenarios, bicentenarios...) que ya ha sido acertado blanco de sátira por varios novelistas contemporáneos, nos dejamos arrastrar por la irresistible corriente al evocar cómo este año se cumple el centenario del nacimiento de Edith Sitwell. Ahora bien, lo que en otras circunstancias constituiría un motivo de solemnes celebraciones, para el caso presente nos atrevemos a augurar una realidad bastante más modesta: algún homenaje aislado y breves semblanzas en los periódicos del proximo día 7 de septiembre. Cierto es que la muerte ha abismado en el silencio y el okvido a quien en vida fuera objeto de fuertes polémicas y centro de apasionada con- 
troversia.

Ya en los años cincuenta, cuando aún le quedaba un decenio de existencia, la popularidad de Edith Sitwell empezó a declinar, en parte por los comentarios despectivos de los críticos en boga y en parte por un cambio en los gustos del público. Frente a los ideales antirrománticos, antisimbolistas y antimodernistas y el tono lacónico y austero del "Movimiento" - con las nuevas voces de Kingsley Amis, Philip Larkin, Donald Davie, D.J. Enright, John Wain, Elizabeth Jennings y Robert Conquest- las últimas producciones de Sitwell podian parecer fruto de una retórica artificial y vacía; su estilo, oscuro, pomposo y recargado de metáforas. En definitiva, si Edith Sitwell en un principio se habia alzado contra el provincianismo y las formas convencionales de la poesía georgiana, ahora se veía desprestigiada por un cierto resurgir de aquellas tendencias. Efectivamente, los integrantes del "Movimiento" coincidian con sus predecesores georgianos en el amor a lo autóctono y el rechazo de las influencias extranjeras, en la preferencia por los temas cotidianos frente a los exóticos, en el cultivo del lenguaje sencillo frente al erudito, en el apego al realismo frente a la fantasía desbordada, en el repudio de todo intelectualismo y afectación. En cualquier caso, aunque durante tal período la lay del péndulo no estuviera favoreciendo la reputación artística de Sitwell, sus pcemas continuaron formando parte de las antologias contemporáneas y en 1954 recibió el nombramiento de "Dame Commander" de la Orden del Imperio Británico. La distinción llegó oportunamente y animó a la autora cuando atravesaba una de sus muchas etapas difíciles, bajo los ataques de revistas como The New Statesman and Nation y The Spectator, que mediante un acoso constante le estaban haciendo dudar de su propia valia. Con este reconocimiento oficial de sus méritos, la escritora sintió un cierto alivio, pero sólo fue un consuelo pasajero en una vida continuamente agitada, llena de conflictos, caracterizada por una lucha incesante desde el principio hasta el fin.

Los últimos años de Edith Sitwell fueron extremadamente duros. A la enfermedad, que le ocasionó una invalidez permanente, se sumaron las dificultades económicas. $Y$ la búsqueda de un refugio en el alcohol no hizo sino empeorar una situación ya muy precaria. En medio de aquella terrible angustia, la escritora redactó su autobiografia, con la colaboración de su fiel secretaria Elizabeth Salter, quien le ayudó a ordenar materiales dispersos (en parte procedentes de la autobiografía que Edith comenzo en los años treinta bajo el título de Family Portrait) y dio a Taken Care Of la forma definitiva con la cual el libro se publicó póstumamente en 1965.

La amargura de una vejez triste ha quedado vertida en las páginas de Taken Care $O f$, donde incluso la infancia se recuerda como una etapa dolorosa. Según el relato, Edith habría sido una niña tímida e introvertida, acomplejada por su físico y marcada para siempre por el rechazo afectivo de parte de sus padres. Ahora bien, aunque no dudemos de la sinceridad de la autora, debemos analizar la autenticidad de sus afirmaciones contrastándolas con los datos objetivos y los testimonios de sus allegados, en particular de sus dos hermanos. Ellos, por ser menores, no fueron testigos de las primeras vicisitudes de Edith, pero compartieron muchas experiencias y en general nos ofrecen una visión más optimista de los mismos hechos. En este sentido, la extensa y bien documentada biografía de Victoria Glendinning constituye una fuente de información absolutamente fiable para hacernos una idea exacata de los aspectos que, por 
delicadeza, los próximos han preferido soslayar. ${ }^{l}$

En realidad, el medio en el que se movió Edith de niña no fue tan hostil como ella, en su ancianidad, se empeñó en creer. Los poemas de Sitwell están llenos de imágenes derivadas de los jardines de la típica casa de campo inglesa señorial que ella habitó. Su gusto por la música y la pintura se desarrolló a través de las clases de piano que recibió de pequeña, de las obras de arte que la rodeaban, de los viajes por Francia e Italia y del contacto con los pintores que retrataron a toda la familia. La temprana lectura de las obras de Shakespeare, junto con la de sus admirados Alexander Pope -cuyos versos de The Rape of the Lock memorizo en secreto-y Swinburne, fue la base de su naciente vocación hacia las letras. Acompañada por su institutriz, Helen Rootham, la joven Edith asistió a conciertos, visitó museos y leyó los poemas de los simbolistas franceses, que su maestra conocía como una experta. Así, Baudelaire, Verlaine y Rimbaud contribuyeron a formar la personalidad literaria de Sitwell y ejercieron un influjo claramente perceptible en su producción poética.

Durante la adolescencia, Edith solía copiar en su cuaderno los pasajes preferidos de sus autores favoritos. Hacia los veinte años, comenzó a incluir composiciones propias. Como nunca abandonó esa costumbre, al final de su vida había completado varios cientos de cuadernos similares, en los cuales se conservan los borradores de sus poemas, cartas, artículos y otros escritos en prosa. A través de tales cuadernos queda patente su cuidadoso método de trabajo, mediante el cual repetía una y otra vez los mismos versos con leves variaciones hasta que se sentía satisfecha con la versión definitiva.

Con la oposición de su madre y una actitud tolerante por parte de su padre, Edith se fue a vivir a Londres en el verano de 1914. Alli, Edith y Helen se instalaron en un apartamento de Pembridge Mansions que pronto se convirtió en centro de reunión de artistas. Rápidamente, Edith se integró en el escenario cultural londinense recibiendo las visitas y siendo a su vez invitada por personajes tan célebres como Sir Edmund Gosse, D.H. Lawrence, Virginia Woolf, T.S. Eliot, Aldous Huxley, Robert Graves, Roger Fry... A través de los contactos, surgieron nuevas oportunidades para publicar e inmediatamente llegó el éxito. Ya en 1913 el Daily Mirror había dado a conocer el primer poema impreso de Edith: "Drowned Suns". En total, serían cinco poemas los que aparecerían en el mismo periódico a lo largo de 1913, dos más en 1914 y cuatro en 1915.

The Mother (1915) fue el primer libro de poesía completo que publicó Edith Sitwell. En el poema que iniciaba y daba título a este volumen de veinticinco páginas ya figuran algunos de los temas recurrentes de su obra ulterior: el amor fracasado, la muerte violenta y el ideal de maternidad frustrado. Con un tono bastante melodramático, el espíritu de la madre asesinada por su propio hijo perdona al fruto de sus entrantas y se culpa a sí misma por no haberlo amado suficientemente.

A The Mother siguio poco despues Twentieth Century Harlequinade (1916), en colaboración con su hermano Osbert, y ese mismo ano ella editó el primer número de Wheels al que seguirían otros cinco más, publicado anualmente desde 1916 hasta 1921.

(1) Victoria GLENDINNING, Edith Sitwell. A Unicorn Among Lions, London, Weidenfeld \& Nicolson Lud, 1981. 
En palabras de Middleton Murry, si Georgian Poetry era como "el gobierno de coalición", Wheels se asemejaba a "la oposición radical". Efectivamente, las sucesivas antologías de Wheels se convirtieron en el órgano de expresión de la vanguardia cultural inglesa.

El espírtu de innovación que movía a la autora cuando editaba Wheels era el mismo que le impulsó a crear Fraçade (1922). Según Edith, fueron sus hermanos quienes le dieron la idea de preparar un espectáculo con música especialmente compuesta para recitar sus poemas. Según Osbert, la ocurrencia partió de los experimentos métricos mediante los cuales Edith pretendía imitar con palabras los ritmos de bailes como el vals y el fox-trot. Los tres hermanos trabajaron con entusiasmo preparando la primera representación, que tuvo lugar en un salón privado abarrotado de famosos. El desarrollo de la velada debió de resultar accidentado, a juzgar por los comentarios de los invitados, pero el rechazo careció de las connotaciones que los Sitwell le añadieron más tarde. Ellos, con una reacción desmesurada, acabaron dando la impresión de que habian sido víctimas de ataques furibundos cuando en verdad habian sido objeto de algo mucho más doloroso para los tres: algunos comentarios despectivos y una graciosa parodia en London Calling.

La incapacidad para soportar la crítica adversa fue una de las constantes en la vida de Edith Sitwell. Por su fuerte personalidad, su firmeza para defender sus convicciones, sus extravagancias, su afán de notoriedad y su carácter impulsivo, ella misma debió comprender que su figura no podía dejar de ser controvertida. $Y$, probablemente, en el fondo, disfrutaba al saberse centro de atención al tiempo que sufría por no ser aceptada. Su comportamiento fue siempre complejo y estuvo plagado de contradicciones; combinaba la timidez con la osadía, la fragilidad con la dureza, el pudor con el exhibicionismo y sentimientos íntimos celosamente guardados con un instinto provocador y agresivo.

Extremista en todas sus actuaciones, Edith profesaba una absoluta lealtad hacia sus amigos y exigía de ellos una fidelidad idéntica. Generosa hasta el heroísmo, su cariño era tan posesivo que inevitablemente venía a desembocar en un desengaño tras otro. El mundo de la ciencia y el arte, aparentemente movido sólo por ideales altruistas, está habitado por seres egocéntricos que fingen interés hacia las obras de quienes les rodean aunque sólo les preocupe su propia labor. Edith se vio sorprendida cuando tuvo que soportar las pequeñas envidias, las mezquindades, la maledicencia y las indiscreciones de sus colegas. Con su tendencia a magnificarlo todo, ella se refería obsesivamente a la traición de los amigos. Otra vez, la realidad era mucho más prosaica de lo que Edith soñaba. Algo vanidosa y necesitada de afecto, no sabía distinguir los halagos de los oportunistas, los cumplidos poco sinceros y las promesas hechas con ligereza. Dado su carácter ingenuo, nada tiene de extraño que repetidamente resultase defraudada por quienes, tras haberla utilizado para escalar, buscaban nuevos apoyos estratégicos mejor situados. En el restringido medio que ella frecuentaba, muchas veces un mismo hecho tribial o una simple anécdota han sido registrados por varias plumas ilustres; una misma sala o un traje han sido descritos con igual minuciosidad por parte de dos o más escritores. Pues bien, resulta patético confrontar algunos de los entusiastas relatos a través de los cuales Edith manifestaba toda su confianza en el futuro de una joven promesa, con los comentarios irónicos mediante los cuales el supuesto genio 
ridiculizaba a su ardiente protectora.

En cuanto a las relaciones sentimentales, Edith se enamoró dos veces, la primera del pintor chileno Alvaro Guevara y la segunda del pintor ruso Pavel Tchelitchew, pero en ambas ocasiones no fue correspondida. Durante bastante tiempo, cuando se abordaba esta cuestión, Edith solía repetir: "Los artistas no deben casarse". Sin embargo, pasados los años, admitió haber sufrido enormemente al saberse admirada pero no amada por los hombres de quienes ella se enamoró. Igual que las frustraciones infantiles imprimieron huellas en su poesía, las decepciones amorosas -en parte ya vividas y en parte todavía sólo presentidas- inspiraron "The Sleeping Beauty". En la original versión de la leyenda que ofrece el poema, el amor queda sin consumar, pues el Príncipe no llega a entrar en el palacio para despertar con un beso a la Bella Durmiente.

The Sleeping Beauty (1924), con su tono elegíaco y nostálgico, representa temática y formalmente la continuación de la fase iniciada con Bucolic Elegies (1923), en ruptura con los experimentos surrealistas de Façade (1922). Sin embargo, Gold Coast Customs (1929) significa en cierto modo una vuelta al espíritu vanguardista de Façade, con un uso parecido del ritmo y la rima aunque encauzados en una dirección opuesta. La alegría y el desenfado de Façade dan paso al horror macabro y a la crueldad de Gold Coast Customs, donde los ritmos del jazz se combinan con los del tam-tam y el comportamiento de la decadente sociedad londinense se asemeja a las bárbaras costumbres de una tribu africana. El pesimismo patente en los versos de Gold Coast Customs recorre la única novela de Sitwell, I Live Under a Black Sun (1937), basada en la vida de Jonathan Swift.

Después de una década de producción en prosa, Edith volvió a escribir poesía. Street Songs (1942) y Green Song (1942) son dos breves volúmenes de poemas, inspirados por la Segunda Guerra Mundial, en los que se aprecia un nuevo cambio de estilo, con predominio de versos largos, a menudo sin rima, símbolos muy elaborados y una mayor madurez técnica. La evaluación crítica de estas obras dio resultados dispares; unos vieron en ellas riqueza y profundidad, mientras que otros desestimaron su vocabulario obsesivamente repetitivo y su tono apocaliptico.

Si la experiencia personal de los bombardeos que asolaron Londres en 1940 inspiraron "Still Falls the Rain" (T.L.S., 6-IX-1941), la descripción de la tragedia de Hiroshima por parte de un testigo ocular impresionó de tal modo a Edith que inmediatamente comenzó a elaborar en su mente el poema que casi un año más tarde empezaría a poner por escrito, "The Shadow of Cain". Este sería el primero de los "Tres Poemas de la Era Atómica", junto con "Dirge for the New Sunrise" y "The Canticle of the Rose". Tales poemas, nacidos de la compasion ante el dolor de los inocentes y de la preocupación por el futuro de la humanidad, acercaron a Edith a un público que hasta entonces le había sido ajeno. Jack Lindsay, tras analizar "The Shadow of Cain" en términos marxistas, aclamó a la autora como poeta —ella odiaba el término "poetisa"de la revolución. ${ }^{2}$ Otros lectores se interesaron más por el contenido filosófico y religioso que por el político. Pero Sitwell, aunque pudiera satisfacer puntualmente a los defensores de una determinada ideología, no militó en ningún partido.

(2) Jack LINDSAY, "The Latest Poems of Edith Sitwell", en: Jose GARCIA VILLA (ed.), A Celebration for Edith Sitwell, Norfolk, New Directions, 1948. 
A primera vista, algunos de los gestos de Edith parecían propios de una feminista, pero su conducta en general no se ajustaba ni al feminismo de su tiempo ni al de hoy; incluso ciertas afirmaciones suyas fueron de naturaleza inequívocamente misógina. En el terreno religioso, no cumplió las expectativas de quienes confiaban en que, tras su conversión al catolicismo, haría proselitismo o se alinearía con otros conversos contemporáneos famosos en actuaciones de gran repercusión social. Tampoco su obra se encuadra en un movimiento o escuela concretos; más bien, las distintas fases de su producción ilustran diferentes tendencias a menudo contrapuestas entre sí.

Según el punto de mira, la actitud de Edith puede ser calificada de falta de coherencia y de miedo al compromiso o bien de rechazo de los moldes hechos y de amor a la libertad para pensar y actuar en cada caso de acuerdo con la propia conciencia. Imprevisible en sus reacciones, Edith siempre sorprendió y muchas veces decepcionó a quienes esperaban que se comportase conforme a ideas preconcebidas. Por eso, nunca tuvo el apoyo incondicional de nadie. Por eso, el centenario de su nacimiento no dará lugar a grandes ceremonias. En todos los campos, Edith optó por la independencia y así su destino fue el de los seres que luchan por ser auténticamente libres: la soledad. 